\title{
THE DIAGNOSTIC USE OF RADIOIODINE IN THYROID DISEASE
}

\author{
Russell Fraser, M.D., F.R.C.P., D.P.M. \\ Professor of Clinical Endocrinology, Postgraduate Medical School of London, London, W.12
}

The usefulness of radioiodine in the assessment of thyroid function is well established, and in most hospitals it is in routine use. But it does not offer us a universally valid test free of any limitations, and it is useful to supplement it with other tests of thyroid function. ${ }^{20}$ For the most part, both the special advantages and limitations of radioiodine tests differ from those of the alternative tests, to which they are therefore complementary; where radioiodine is inapplicable or its results unexpected from the clinical picture, recourse to another test will usually clarify the problem. However, it must be admitted that the reliable detection of partial thyroid failure by any test remains difficult. As a consequence opinions differ on the syndrome, incidence and treatment of mild hypothyroidism. For example, a recent controversy about ' metabolic insufficiency,' which was said to respond to triiodothyronine but not to thyroxine treatment, has only been settled by 'double-blind' testing of the response to treatment, e.g. Sikkema. ${ }^{60}$ Some may think that the technically delicate and costly protein-bound iodine test (P.B. ${ }^{127} \mathrm{I}$ ) has filled this loophole. However, Lowrey and Starr, ${ }^{38}$ who for long have been the protagonists of this test and so perform it more accurately than most, found an incidence of $4-9 \%$ of subnormal values amongst various sample groups of the normal working population. These people had no symptoms, so that it is likely that these findings reflect the error of the test rather than of the frequency of a real endocrine abnormality. It must be admitted that radioiodine offers no help here. This is even more a blind spot for radioiodine than for the other tests, but it is practically its only one, provided the ingestion of drugs which might affect thyroid function can be excluded. Radioiodine tests can be used to demonstrate or exclude either complete and near complete failure or any increased activity of the thyroid; and for these purposes their routine methods surpass any other test of thyroid function in efficiency, i.e. in simplicity, sensitivity and accuracy. They can also be used to define more precisely the nature of the disorder in certain thyroid diseases. However, as with all tests, clinically unexpected results alwayg call for careful re-examination of the patient, and; perhaps rechecking with other tests.

Recent Changes in the Methods Being Used

In the last decade the newer scintillation counter $\overrightarrow{80}$ have made possible more accurate counting of liquid samples so that plasma tests which have certain theoretical advantages over uptake testscan be used routinely and accurately with smalk amounts of radioactivity (see Fig. 2). For routine purposes, however, it is advisable to include eithe neck or urine measurements, since tests based 1 i a single phase of iodine metabolism may sor times be misleading. The availability of the short lived isotope ${ }^{132} \mathrm{I}$ (half-life $=2 \frac{1}{4}$ hours) permit tests which give less than $1 / 30-1 /$ Iooth of the radiation dose to the thyroid in tests with the usual isotope ( ${ }^{131} \mathrm{I}$ : half-life $=8$ days given). Thus ${ }^{132} \mathrm{I}$ is useful either for the detection of thyro toxicosis in children or for investigations requiring frequent testing. But ${ }^{131}$ I will probably remain. the isotope of choice for routine diagnostic use $\frac{0}{3}$ since the late plasma test ( 48 hours) often distin guishes the occasional avid hyperplastic non-toxic goitre from thyrotoxicosis, and urine or late nect. measurements are the most suitable tests for the recognition of hypothyroidism.

Isotopic detection methods have been applied? after chromatographic or electrophoretic separa tion, ${ }^{56}$ to the iodoproteins and the protein-bound. or extracted iodoaminoacids of urine; ; 17,24 , 2/ plasma; $; 0,68,69$ or thyroid digests or homor genates $; 0$ and this has helped define the natures of the disordered thyroid hormone metabolism in certain diseases. These methods have permitted the assessment of the patient's metabolism of either iodotyrosines ${ }^{62}$ or iodothyronines ${ }^{25}$ in various diseases. Radioiodine has also made possible the development of bioassays of thyrotrophin suffio ciently sensitive for application to human plasm samples. ${ }^{1,}$ 6, 42 
The measurement of the secretion rate of thyroid hormone, one of the ultimate objects in clinical tests of thyroid function, remains a complex problem. Riggs ${ }^{54}$ has estimated the normal value to be about 7oug. per day. Clearly the PB ${ }^{131}$ I test's reflection of this rate may be falsified by variations in the size of the thyroid store or in the nature of the thyroid hormones secreted, in some diseases. More indirect methods, which must also incorporate some supplementary ${ }^{127} \mathrm{I}$ estimation to derive specific activity, are too com: plex for routine clinical use ;4, 7, 44 these give normal values approximating to those of Riggs. ${ }^{54}$ Even so, interpretation is difficult since the thyroid hormones are normally secreted as about 90-95\% thyroxin mixed with other thyronines, mainly triiodothyronine. ${ }^{2,3,48}$

\section{Iodine Metabolism}

Clearly radioiodine traces iodine metabolism and only indirectly thyroid function. Herein lies the main limitation in its clinical use, since the results may be modified by the previous ingestion of an unusual amount of iodine or of drugs which affect iodine metabolism. Clinically such distortions are usually only produced by drugs, for the naturally iodine-deficient areas or those where the usual diet is high in fish or other iodinecontaining foods should be known to the clinicians. Fortunately, in most regions, the mean iodine intake does not vary sufficiently to prevent the rate of radioiodine metabolism reflecting thyroid function. Apparently the body's only adjustment to compensate for the varying daily iodine intake is a changing rate of thyroid cell activity; for the renal clearance of iodine remains uninfluenced by great variations in iodine intake, and in all circumstances runs closely parallel with that of urea $;^{29}$ thus the thyroid gland is able to maintain a steady rate of hormone secretion by virtue of this changing uptake and its large store.

Within the thyroid gland (Fig. I) the iodine may be considered as passing through three main pools. From the body's more dilute iodide pool it is first concentrated into ( $\mathrm{I}$ ) the thyroid's iodide pool; thence it becomes organically bound into thyroglobulin, initially by binding to tyrosine and so entering into the hormone's precursor, or (2) iodotyrosine pool (of both mono- and di-iodotyrosine); finally after full synthesis into the stored hormone it enters (3) the thyronine pool (of thyroxine and triiodothyronine); from the last, after hydrolysis of the thyroglobulin, it is eventually secreted into the blood stream (mostly as thyroxine but with 5-10\% triiodothyronine). As thyroglobulin is hydrolysed to release the hormone or the thyronines, the simultaneously
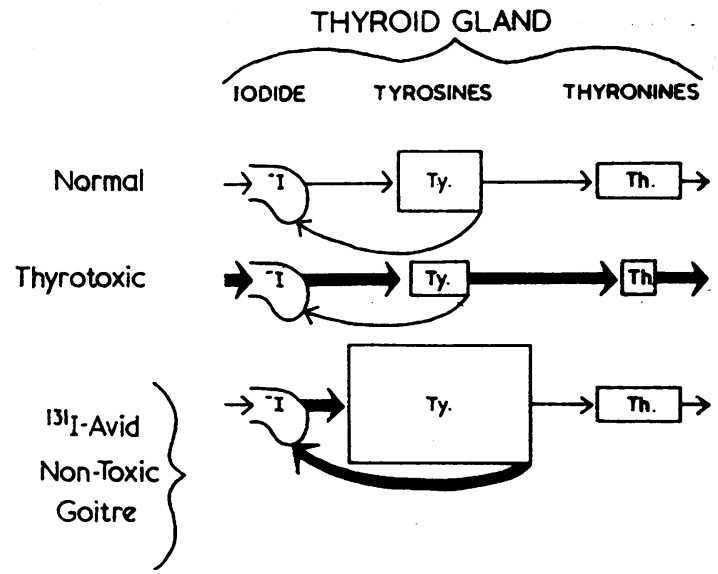

Fig. 1.-Iodine metabolism within the thyroid gland (schematic).

Note increased rate of transfer at all steps in thyrotoxicosis, but only at the step from iodide to tyrosines in the avid non-toxic goitre.

released iodotyrosines are deiodinated by the gland's deiodinase to iodide which then re-enters the cycle of iodide synthesis in the thyroid gland.

Hence a counter over the thyroid gland will reflect initially a double process, both the concentrating into the thyroid's iodide pool and the simultaneous organic binding. Within the first hour full mixing of the ${ }^{131}$ I label has usually occurred between the body's and the thyroid's iodide pools; and thereafter, with this mixing completed and maintained, the counter really reflects the rate at which organic fixation of iodine is proceeding in the thyroid. Thus most measurements of thyroid uptake, especially the late ones at 24 or 48 hours, are mainly indices of the rate of iodine fixation or organic binding by the thyroid; this rate is, of course, dependent on the concentration of iodide within the gland, so that it may be altered by abnormalities in the concentrating mechanism.

The above considerations explain how a few of the hyperplastic non-toxic goitres may have an avid thyroid uptake, although secreting merely a normal amount of thyroid hormone. For, as indicated in Fig. I, the thyroid gland also incorporates a recycling mechanism, whereby any iodotyrosines freed by the proteolysis which releases the hormone, are deiodinated so that their iodine is released and again enters the first step of organic binding of iodine. Thus if the transfer of iodine from iodotyrosine to thyronine is impaired, this recycling will take a larger proportion of the labelled iodine than does thyronine synthesis; and so the thyroid uptake may be high without any increased rate of formation or of release of thyronine, i.e. without hyperthyroidism. 


\section{Standard Clinical Tests of Total Thyroid Function (Radioiodine)}

These tests, which measure the speed of iodine transfer, comprise the main clinical use of radioiodine in the diagnosis of thyroid disorders. Appropriate procedures ( $v$. infra) can measure the efficiency of various steps in this process $; 52$ in lymphadenoid and certain congenital goitres they may help to define the defect.

\section{Types of test}

An enormous number of tests have been devised, but they may be grouped into: (i) Early uptake tests (up to 6 hours), (ii) late uptake tests (24 and 48 hours), (iii) urine or indirect uptake tests, (iv) plasma organic iodine tests.

(i) Early uptake measurements have the advantage of rapidity so that ${ }^{132}$ I may be used (v.s.) but also several disadvantages which include an insensitivity to decreased thyroid function, a variability arising from small daily fluctuations, difficulties associated with the large extrathyroid component in the neck radioactivity measurement, and a dependence on precise timings. Nevertheless, a single neck measurement at io minutes probably gives as sensitive an index of increased thyroid function as any other test, ${ }^{28}$ though it is not as specific as the plasma test (v. infra). Estimation of the thyroid clearance rate requires more complex measurements and has little advantage over other early uptake tests. It may be indexed by measuring the neck/thigh ratio at 2 hours, which eliminates the need for a measurement of the dose given but gives units depending on geometry and so varying from one laboratory to the next. Simplified methods for estimating the thyroid clearance rate have been described; they include the use of two neck measurements and a midpoint blood sample, using neck and thigh measurements, ${ }^{18}$ or using two neck measurements and a urine sample. ${ }^{10}$

(ii) Late neck measurements (24- and 48-hour uptakes, normal $=25-50 \%$ ). These commonly used measurements are excellent for revealing hypothyroidism, but much less satisfactory for revealing increased thyroid function, though nevertheless adequate for this purpose in most patients. Ideally, the peak uptake, which may vary from 2 to 48 hours, should be obtained from plotting a serial curve, but this is usually impracticable and unnecessary. With standard apparatus these neck measurements should be accurate to within about $\pm 5 \%$; but the degree of accuracy depends largely on the technique used to ensure good geometry and comparable counting of the standard and of the neck. Some error from varying thyroid size and depth can never be fully eliminated. (iii) Urine or indirect uptake measurements; whe properly designed (i.e. subdivided into three more samples ${ }^{21}$ ) and given to a reasonably co operative patient, have the advantage of being sensitive to both hyper- and hypo-thyroidism: In this respect they have the advantage over 䄳 other types of test. Irregular distribution between the samples suggests errors in the collection of urine or incomplete emptying of the bladde When unexpectedly low uptakes are found, it also convenient to supplement this test by $\frac{\rho}{\partial}$ simple chemical measurement of iodide excess t 8 pick up unsuspected previous dosing wit iodine. ${ }^{21}$

(iv) Plasma organic iodine measurements (Fig. $2 \vec{W}$ This useful test (best done at 48 hours) unforo tunately is not reliable for revealing hypothyroids ism because of the extremely low values occa. sionally found in normal subjects. Furthermores high ones are found in partial thyroid failure associated with a small thyroid hormone store e.g. in the earlier stages of lymphadenoid goitr局 (see Fig. 2). However, these apparently 'falsee positives ' are usually revealed as such in untreated. subjects by the normal or low associated 48 -houk neck uptake, and so these two measurements should be made together. Similar findings due to a small thyroid store may also be encountere after a recent thyroidectomy ${ }^{16}$ or after radro:iodine treatment; here the uptake may also क्षे high. However, the values are usually normalin the ${ }^{131}$ I-avid non-toxic goitres (see Fig. 2) and always high in hyperthyroidism.

The result of this measurement is best expresse as the concentration of P.B. ${ }^{131} \mathrm{I}$ per litre ot plasma. ${ }^{30,66}$ Most of the radioiodine in plasm at 48 hours or later is hormonal so that a useful index, almost as good as any other P.B. ${ }^{131}$ I index. in the absence of renal failure, is obtained merely from the total 48 -hour plasma ${ }^{131} \mathrm{I}$. Sometimes. various special ratios are used instead, but the above simpler procedures have advantages ove all of these. 'The conversion ratio,' i.e. the ratio of the concentration of protein-bound to inorganic iodine ${ }^{131} \mathrm{I}$, suffers from its great susceptibility to any errors in the technique of chemical separation and to errors in measuring the small amounts of iodide. The salivary test ${ }^{65}$ takes advantage of the fact that iodide (and no other ${ }^{131} \mathrm{I}$ ) is concentrated from plasma into saliva, normally about 30 -fold But this advantage is minimized by the othef factors which vary the concentration of iodide in saliva-the salivary secretion rate and the varying amount of mucus in saliva. Another ratio, the 48 to 2 -hour plasma ratio, ${ }^{5}$ has also been used, but has little advantage over the simple 48-hou 5 P.B. ${ }^{131}$ I measurement.

(v) The combined use of two or three tests. Clearl $y_{\mathbb{D}}$ 


\section{HR P. B. I. ${ }^{\mid 31}$}

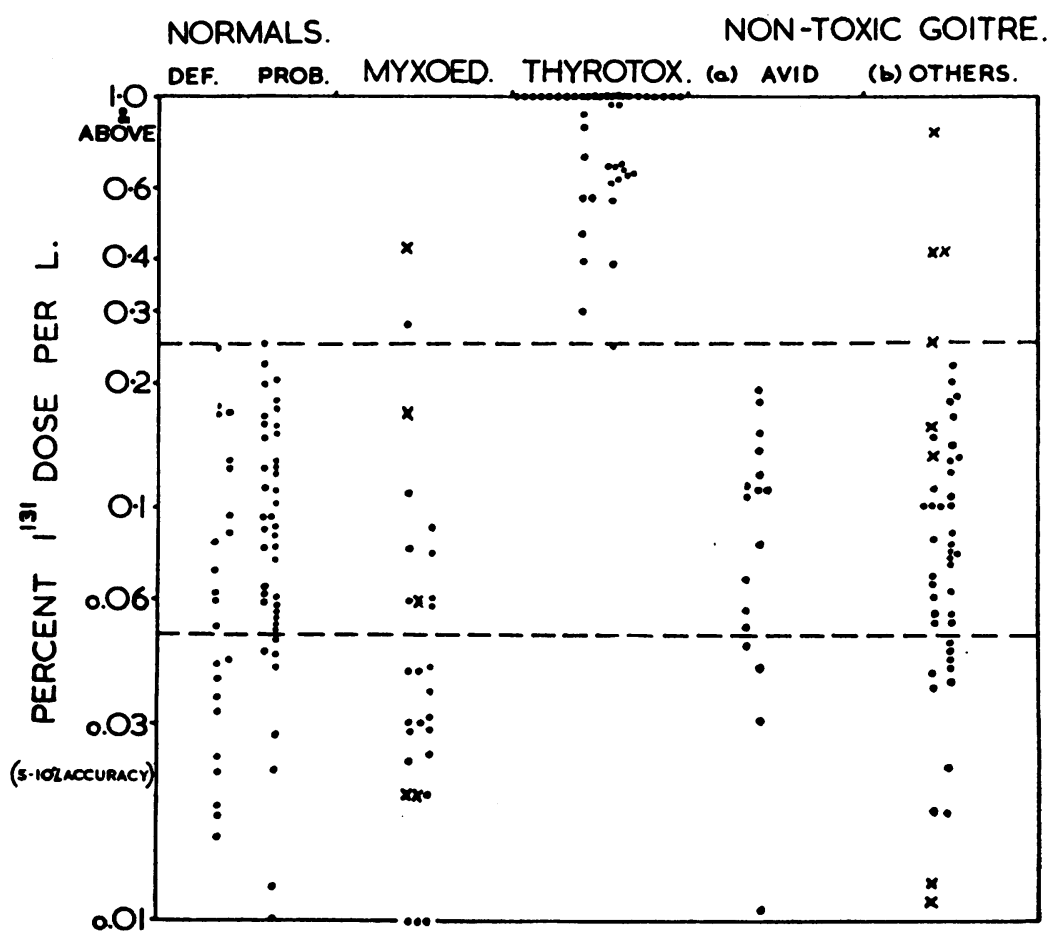

FIG. 2.-Results of 48 -hour plasma protein-bound ${ }^{131}$ I test in cases of previously untreated thyroid disease ( $x=$ lymphadenoid goitre shown by thyroid biopsy).

Note.-(1) Normal range $0.05-0.25 \%$ dose per litre, but a small proportion gives very low values (due to recent high iodine intake). (2) All thyrotoxic values are high and usually well beyond normal range. (3) Only other high values (in these untreated cases) =lymphadenoid goitre, either presenting as myxoedema or as nontoxic goitre-note that none had an associated avid uptake of ${ }^{131} \mathrm{I}$. (4) Values normal in all other non-toxic goitres, and particularly in all avid non-toxic goitres. (5) Test of no value in diagnosis of myxoedema. (6) A 5-10\% accuracy is possible.

there are several advantages in using a combination of simple tests which measure slightly different aspects of iodine metabolism. A good economical combination is a urine test, a 48 -hour neck measurement, and a 48-hour plasma measurement. More complicated and fuller studies can then be reserved for special problems.

\section{Interpretation}

The normal uptake and discharge have been shown to vary with age, as does the basal metabolic rate, 41,59 though clinical standards may not need such a fine correction. An adaptation by the thyroid to decreased tissue utilization has been shown as the probable basis of this change. ${ }^{70}$ With hyperthyroidism a normal or low result in both uptake and plasma tests is extremely rare and usually excludes the diagnosis, provided there has been no previous abnormal intake of iodine, though very occasionally this may be found with multinodular goitres. ${ }^{39}$ A high uptake will be found in a small proportion of cases of non-toxic goitre (those hyperplastic and enlarging), as well as in conditions of iodine deficiency such as occurs after the administration of antithyroid drugs, though here the P.B. ${ }^{131}$ I is generally normal (though not with extreme iodine deficiency after antithyroid drugs). On the other hand, as already mentioned, high P.B. ${ }^{131}$ I values may be found when the thyroid store of hormone is reduced after thyroidectomy or after radioiodine treatment and also with lymphadenoid goitre.

A high uptake of ${ }^{131}$ I may be found in association with clinical hypothyroidism in lymphadenoid goitre, after antithyroid drugs or in congenital goitres with defective hormone synthesis. Com- 
plete thyroid failure can be shown with ${ }^{131} \mathrm{I}$, but, as already noted, the possibility of depressed uptake due to drugs must always be remembered and partial thyroid failure may not show any abnormal result. Subacute thyroiditis is also characterized by absent thyroid uptake but will show clinical evidence of normal or increased thyroid secretion. In clinical hypopituitarism short of complete thyroid failure there may be a normal thyroid uptake of radioiodine, albeit associated with an excessively low P.B. ${ }^{131} \mathrm{I}$ value. ${ }^{19}$ On the other hand, radioiodine has proved extremely valuable for testing hypophysectomized subjects for the completeness or at least adequacy of this operation-complete hypophysectomy always showing a very reduced uptake; a clinically satisfactory operation for secondary breast carcinoma should achieve this test standard..$^{32}$

There have been several studies of the lymphadenoid goitre's handling of ${ }^{131} \mathrm{I}$. The uptake may be of any type but there is always a rapid discharge, which is characteristically accelerated when perchlorate is given at one hour. The gland does not respond to T.S.H., suggesting that it is already under maximal stimulation. ${ }^{12,43}$ Owens and McConahey ${ }^{45}$ demonstrated an unusual iodinated protein in the serum of some patients. These ${ }^{131} \mathrm{I}$ tests in this condition indicate both defective storage and incomplete synthesis of the hormone.

To assess a previous diagnosis of thyroid failure in a patient already taking thyroid, T.S.H. may be given 24 hours before a radioiodine test after which a defective uptake implies some thyroid failure. Einhorn and Larsson ${ }^{13}$ have given details of the timing of the different human responses to injected T.S.H. and of the effective dose.

\section{Recent Developments in Radioiodine Tests}

Red cell uptake of triiodothyronine. For this test a sample of the patient's red cells is removed and the rate of entry of radioactive triiodothyronine into them is measured in vitro. Studies using this test on a large number of patients have shown that it separates without overlap people with high, normal, and low thyroid function. ${ }^{27}$ However, abnormal results are also found due to abnormal levels of thyroxine-binding protein (v. infra), and so occur in pregnancy, after oestrogen, in nephrosis and in liver disease, as well as for unexplained reasons in pulmonary insufficiency, and after anticoagulants. A normal result was found with iodide myxoedema. Possibly analogously, it may be noted that red blood cells labelled with ${ }^{32} \mathrm{P}$ lose this radioactive label more rapidly in thyrotoxicosis, and less rapidly than rormal in myxoedematous subjects. ${ }^{14}$
Tests to distinguish the avid non-toxic goitre from thyrotoxicosis: the iodide repletion test, ${ }^{8}$ te iodide inhibition test, ${ }^{15}$ and the thyroid hormogize suppression test. ${ }^{67}$

Two different types of iodide response tests c\$n apparently distinguish thyrotoxicosis from other goitres avid for ${ }^{131} \mathrm{I}$. In the first, the iodide rep tion test, retesting with ${ }^{131}$ I at four weeks affer two weeks of daily doses of ro $\mathrm{mg}$. potassium iodide, reveals the thyrotoxic glands still avod for ${ }^{131} \mathrm{I}$, but the others showing a normal response. In the second test a smaller dose of iodide ( $\mathrm{Ig}_{\mathrm{e}}$ mg.) is added to a second dose of ${ }^{131}$ I given 24 hours after a standard test; only in thyrotoxic glands is this found to depress both the uptatse and the discharge of ${ }^{131} \mathrm{I}$, thus showing that the thyrotoxic gland is specially susceptible to this acute iodide inhibition.

The thyroid hormone (usually triiodothyrone) suppression test continues to be a useful methed for making the same distinction as these tixo iodide tests. Administration for seven days $\overrightarrow{\text { cof }}$ about the normal requirements for thyroid hofmones or $60 \mu \mathrm{g}$. of triiodothyronine/day, or preferably of $120 \mu \mathrm{g}$./day, will suppress the norme uptake of radioiodine and also the thyroid avidity found in hyperplastic non-toxic goitres of iodine deficiency, but will not suppress the uptake of thyrotoxicosis nor the uptake of sồ cases of nodular goitre. ${ }^{23,67}$ Johnson et al..$^{33}$ hra shown that the normal response on this test includes suppression of both the uptake and the discharge. In thyrotoxicosis, on the other hang, neither of these parameters is affected, even aftês very high doses of thyroid hormone. Clearly, regulation of the thyroid secretion rate is deordered in thyrotoxicosis, though this test dos not indicate whether the site of this disorder is the hypothalamus, the pituitary or the thyroid. Other associated changes seen during this tes have also been studied. ${ }^{53}$

'Peripheral utilization.' Measurements of the rate of disposal of injected ${ }^{131}$ I-thyroxin or -triiodethyronine, while giving some indication of peripheral utilization of thyroid hormone, may difficult to interpret because of the influence sof TBP level, the concentration of free thyroxis liver function, etc. One author found that botb the slower turnover in myxoedema and the faster turnover in thyrotoxicosis return to normal on the restoration of normal thyroid function ; ${ }^{64}$ whise Ingbar ${ }^{30,31}$ found this rate still raised in treated thyrotoxic subjects and also in their euthyrogi relatives. ${ }^{131} \mathrm{I}$-labelled thyrotoxic plasma w $\overrightarrow{\mathrm{FS}}$ removed more rapidly than normal plasma e $\frac{+}{p-}$ riched to the same concentration of hormone $\frac{26}{0}$ This measure of the rate of disposal of hormone has also been reported high in otherwise euthy- 
roid subjects with paroxysmal cardiac arrhythmias. ${ }^{34}$

\section{More Detailed Parameters of Thyroid Function which Radioiodine can Assess}

\section{Thyroid Hormone Biosynthesis and Goitrogenesis}

The transformation by the thyroid of iodide to secreted hormone (reviewed by Roche and Micel, ${ }^{57}$ Pitt-Rivers and $\mathrm{Tata}^{50}$ ) has the following main steps: (i) The concentration of iodide into the gland, (ii) the oxidative organic binding of this as mono- and di-iodotyroxines, (iii) the coupling of these to form the thyronines, most of which is thyroxine, (iv) final hydrolysis of the stored thyroglobulin with release of the thyronines into the blood, while simultaneously (v) a deiodinase returns most of the tyrosine iodine back to iodide for further synthesis. Congenital or other derangements in this synthesis may obviously cause goitrous cretinism or hypothyroidism, while lesser defects may merely give rise to a goitre.

Many goitrous cretins have now been tested by means of specific tests using ${ }^{131} \mathrm{I}$ and defects in each of the last four steps* have been found. ${ }^{36,71}$ A defect in step (ii) (the iodination of tyrosine) is easily recognized by finding an avid thyroid uptake which is discharged by thiocyanate or perchlorate $;^{61}$ one at step (iv) (thyroglobulin hydrolysis) from the release into the circulation of protein- or pepdide-linked ${ }^{131}$ I $^{11}$ similar to that released in some cases of carcinoma or thyroiditis ${ }^{62}$ one at step (v) (deiodination) by demonstrating the patient's defective ability to metabolize injected labelled diiodotyrosine ${ }^{63}$ and one at step (iii) (coupling) either from thyroid digest studies or by finding an excess of plasma proteinbound iodine which can be identified as an iodotyrosine. ${ }^{40,68}$ In this group of cases the P.B. ${ }^{127}$ I or ${ }^{131}$ I may be high, low or normal since its proportion of thyroxine is both variable and subnormal. On radioiodine tests these glands show the features of secondary hyperactivity; i.e. thyroid hormone administration depresses the patient's avidity for ${ }^{131} \mathrm{I}$, albeit slowly at times, and also returns P.B. ${ }^{127}$ I to normal. ${ }^{37}$

Various studies of iodine metabolism have been made in the regions of endemic goitre and have confirmed the presence of iodine deficiencies; but similar evidence of deficiency has also been found in people without goitres in these areas. ${ }^{35,58}$ Studies of gland hydrolysates from non-toxic goitres have revealed a low di- to mono-iodotyrosine ratio, DIT/NIIT.49 An interesting type of drug goitre may very occasionally follow after the administration of large doses of iodide for a long

* An example with a defect in step (i) has also recently been found. period. ${ }^{46,47}$ Within one or two days of stopping the iodide the glands become avid for radioiodine, and ${ }^{131}$ I tests show them to be abnormally sensitive to the inhibitory effects of iodide. ${ }^{47}$

\section{The Thyroxine-binding Protein (TBP)}

As is now emerging for other hormones, most of the thyroid hormone circulates bound to a specific protein (TBP), which has a high affinity for thyroxine but a lesser affinity for its analogues. ${ }^{50,56}$ Addition of thyroxine to serum will eventually saturate the protein, after which the excess moves on to a looser binding to the albumin. The concentration of TBP in the plasma may be measured by observing the electrophoretic distribution in the plasma of added ${ }^{131}$ I-thyroxine, and also the change in this distribution which follows a further addition of an exact amount of unlabelled thyroxine, from which the level of free thyroxine can also be deduced. ${ }^{56}$ It is the concentration of free thyroxine which probably determines the hormonal drive to the tissues. The concentration of circulating TBP changes little in thyroid disease, but it is strikingly raised in pregnancy, probably due to the effect of the raised oestrogen levels, ${ }^{55}$ and lowered in nephrosis, probably due to its loss into the urine. ${ }^{22}$

\section{REFERENCES}

I. ADAMS, D. D., an 1 PURVES, H. D. (1957), Metabolism, 6, 26. 2. ARONS, W. L., and HYDOVITZ, J. D. (1959), f. clin. Endocr., 19, 548 .

3. BENUA, R. S., and DOBYNS, B. M. (1955), Ibid., 15, I 18.

4. BERSON, S. A., and YALOW, R. S. (1954), F. clin. Invest., 33, 1533 .

5. BLONDAL, H. (1952), Brit. F. Radiol., 25, 260.

6. BOTTARI, P. (1960), Ciba Colloquia on Endocrinology (to be published). 7. BRENNER, O., BLACK, A. B., and GADDIE, R. (1954),
Clin. Sci., 13, 441.

8. BURRELL, C. D., and FRASER, R. (1957), Quart. f. Med. N.S., 26, 559.

9. CAMERON, C. (1960), Biochem. F., 74, 329, 333.

10. COENEGRACHT, J., and FRASER, R. (1955), $\boldsymbol{f}$. Endocr., $12,185$.

I I. DeGROOT, L. J., POSTEL, S., LITVAK, J., and STANBURY, J. B. (1958), f. clin. Endocr., 18, 158 .

12. DONIACH, D., and HUDSON, R. V. (1957), Brit. med. F., i, 672 .

13. EINHORN, J., and LARSSON, L-G. (1959), F. clin. Endocr., 19, 28.

14. ERMANS, A. M. (1958), Acta Medica Belgica (thesis).

15. FEJNBERG, W. D., HOFFMAN, D. L., and OWEN, C. A. (1959), F. clin. Endocr., 19, 567.

16. FELLINGER, K., HÖFER, R., and VETTER, H. (1957), Ibid., 17,483 .

17. FLETCHER, K. (1957), Biochem. F., 67, 136 and 140.

18. FOOTE, J. B., and MACLAGAN, N. F. (195I), Lancet i, 868.

19. FRASER, R. (1957a), Ciba Foundation Colloquia on Endocrinology, 10, 248.

20. FRASER, R. (1957b), Postgrad. med. F., 33, 312-316.

21. FRASER, R., HOBSON, Q. J. G., ARNOTT, D. G., and EMERY, E. W. (1953), Quart. F. Med. N.S., 22, 99.

22. FREINKEL, N. (1957), Endocrinology, 61, 448.

23. GREER, M. A., and SMITH, G. E. (1954), f. clin. Endocr., 14,1374 .

24. HALES, I. B., and FRASER, R. (1959), J. Endocr., 19, 193.

25. HALES, I. B., and DOBYNS, B. M. (1960), F. clin. Endocr., 
26. HAMOLSKY, M. W., ELLISON, H. E., and FREEDBERG, A. S. (1957), Ұ. clin. Invest., 36, 1486.

27. HAMOLSKY, M. W., GOLODETZ, A., and FREEDBERG, A. S. (1959), Y. clin. Endocr., 19, 103.

28. HIGGINS, H. P. (1959), Ibid., 19, 557.

29. HLAD, C. J., and BRICKER, N. S. (1954), Ibid., 14, 1539

30. INGBAR, S. H., FREINKEL, N., HOEPRICH, P. D., and ATHENS, J. W. (1954), Ұ. clin. Invest., 33, 388 .

31. INGBAR, S. H. (1958), Endocrinology, 63, 256.

32. JOPLIN, G. F., and FRASER, R. (1960), Proc. roy. Soc. Med. $53,81-84$.

33. JOHNSON, D. E., SOLOMON, D. H., and GREER, M. A. (1959), F. clin. Endocr., 19, 317.

34. KURLAND, G. S., GOLODETZ, A., HAMOLOSKY, M. W., and FREEDBERG, A. S. (1959), Ibid., 19, 92.

35. LAMBERG, B. A., WAHLBERG, P., WEGELIUS, $O$. HELLSTRÖM, G., and FORSIUS, P. I. (1958), Ibid., 18, 991 .

36. LELONG, M. JOSEPH, R. CANLORBE, P JOB, J-C. and PLAINFOSSE, B. (1956), Arch. franc. Pédiat., 13, 34I.

37. LEVY, R. P., KELLY, L. W., and JEFFERIES, W. MCK. (1956), Amer. F. med. Sci., 231, 61.

38. LOWREY, R., and STARR, P. (1959), f. Amer. med. Ass., I7I, 2045 .

39. McCONAHEY, W. M., KEATING, F. R. Jr., and POWER, M. H. (1949), F. clin. Invest., 28, 191.

40. McGIRR, E. M., HUTCHISON, J. H., and CLEMENT, W. E. (r959), Scot. med. F., 4, 107.

41. MacGREGOR, G. A., and WAGNER, H. (1958), Lancet ii,

42. McKENZIE, J. M. (1958), Endocrinology, 62, 865.

43. MORGANS, M. E., and TROTTER, W. R. (1957), Lancet i, 553.

44. ODDIE, T. H., MESCHAN, I., and WORTHAM, J. (1955), F. clin. Invest., 34, 95.

45. OWEN, C. A., and McCONAHEY, W. M. (1956), F. clin. Endocr., 16, 1570.

46. PALEY, K. R., SOBEL, E. S., and YALOW, R. S. (1958), F. clin, Endocr., 18, 79 .
47. PARIS, J., McCONAHEY, W. M., OWEN, C. WOOLNER, L. B., and BAHN, R. C.'(1960), Ibid., 20, 5 . 48. PIND, K. (1957), Acta endocr., 26, 263.

49. PITT-RIVERS, R., HUBBLE, D., and HOATHER, W. (1957), F. clin. Endocr., 17, 1313.

50. PITT-RIVERS, R., and TATA, J. R. (1959), "The Thyroig Hormones ' (Pergamon Press, London).

51. POCHIN, E. E. (1950), Lancet, ii, 41 .

52. RALL, J. E. (1956), Amer. F. med., $20,719$.

53. RICH, C. (1958), F. clin. Endocr., 18, 1024.

54. RIGGS, D. S. (1952), Pharmacol. Rev., 4, 284.

55. ROBBINS, J., and NELSON, J. H. (1958), $\mathcal{F}$. clin. Invest., $3 \overline{\bar{U}}$ I53.

56. ROBBINS, J., and RALL, J. E. (1957), Recent Progr. Hormong Res., 13, I61.

57. ROCHE, J., and MICEL, R. (1955), Physiol. Rev., 35, 583. @

58. ROCHE, M., DeVENANZI, F., VERA, J., COLL, Fîn SPINETTI-BERTI, M., MENDEZ-MARTINEZ, J., GERADI, A., and FORERO, J. (1958), f. clin. Endocro 18, 991.

59. ROSENBERG, G. (1958), Ibid., 18, 516.

6o. SIKKEMA, S. H. (1960), Ibid., 20, 546.

61. STANBURY, J. B. (1951), Ibid., 11, 740.

62. STANBURY, J. B., and LITVAK, J. (1957), Ibid., 17, 654. ஜृ

63. STANBURY, J. B., and MCGIRR, E. M. (1957), Amer. F. Med 22, 712.

64. STERLING, K. (1958), f. clin. Invest., 37, 1348.

65. THODE, H. G., JAIMET, C. H., and KIRKWOOD, S. (1954) New Engl. F. Med., 251 , 129.

66. WAYNE, E. J. (1954), Brit. med. F., i, $41 \mathrm{I}$.

67. WERNER, S. C. (1956), F. clin. Invest., 35, 57.

68. WERNER, S. C. BLOCK, R. J., MANDL, R. H., and KASSENAAR, A. A. H. (1957), , 69. WERNER, S. C., and BLOCK, R. J. (1959), Nature, 183, 406. 70. WILANSKY, D. L., NEWSHAM, L. G. S., and HOFFMAN, M. M. (1957), Endocrinology, 61, 327.

7 r. STANBURY, J. B., and CHAPMAN, E. M. (1960), Lance i, II62.

\section{ENDOCRINE TUMOURS}

(Postgraduate Medical Journal, March 1960)

Price 6s. 6d. post free

ISLET-CELL TUMOURS AND PEPTIC ULCERATION

James B. Gibson, M.D., M.R.C.P.(Edin.), and Richard B. Welbourn, M.A., M.D.(Camb.), F.R.C.S.

ISLET-CELL TUMOUR OF THE PANCREAS, WITH HYPOGLYCAEMIA

Robert S. Monro, F.R.C.S.

PHAEOCHROMOCYTOMA

J. T. Wright, D.M., M.R.C.P.
VIRILIZING SYNDROMES

Ivor H. Mills, Ph.D., M.D., M.R.C.P.

BILATERAL POLYCYSTIC OVARIES

David Ferriman, D.M., M.R.C.P.

FEMINIZING TUMOURS OF THE TESTIS

P. Paton Philip, M.Chir., F.R.C.S.

CONN'S SYNDROME

T. M. Chalmers, M.D., M.R.C.P.

Published by

THE FELLOWSHIP OF POSTGRADUATE MEDICINE

60, Portland Place, London, W.1 